\title{
Treating Veterans of Iraq and Afghanistan: A State Needs Assessment of Civilian Physicians in Internal and Family Medicine
}

\author{
Sally A. Koblinsky ${ }^{1^{*}}$, Katie M. Hrapczynski ${ }^{2}$ and Leigh A. Leslie ${ }^{3}$
}

Department of Family Science, School of Public Health, University of Maryland, College Park, USA

"Corresponding author: Sally A. Koblinsky, Professor, Department of Family Science, School of Public Health, University of Maryland, College Park, USA, Tel: 301-405-4009; E-mail: koblinsk@umd.edu

Rec date: Jan 29, 2015, Acc date: Mar 2, 2015, Pub date: Mar 05, 2015

Copyright: (c) 2015 Koblinsky SA, et al. This is an open-access article distributed under the terms of the Creative Commons Attribution License, which permits unrestricted use, distribution, and reproduction in any medium, provided the original author and source are credited.

\begin{abstract}
Background: With the return of troops from Afghanistan and Iraq, growing numbers of primary care physicians in the United States are treating veterans and their families for war-related conditions. However, little is known about civilian providers' capacity to address the needs of this population.
\end{abstract}

Objectives: This study sought to assess civilian internists and family physicians' knowledge, confidence, practices, and training needs in treating war-related conditions of recent veterans and their family members.

Method: An anonymous needs assessment survey was administered online by the Maryland Board of Physicians. A convenience sample of physicians in internal and family medicine $(\mathrm{N}=145)$ reported on their treatment and referral practices, knowledge and confidence in treating 14 veteran conditions, and preferred training modalities.

Results: Only $12 \%$ of respondents were military veterans, but $42 \%$ of internists and $22 \%$ of family physicians reported some training in a Veterans Administration or Department of Defense facility. Although more than $70 \%$ of respondents treated veterans in their practices, approximately $60 \%$ never screened for military status and more than $40 \%$ never referred patients for VA care. Internists and family physicians did not differ significantly in their knowledge or confidence in treating any of the targeted conditions. Overall, both groups reported low knowledge of best practices and limited confidence in treating war-related conditions of veterans and family members. Respondents reported substantial interest in training to treat veteran patients through face-to-face trainings and webinars.

Conclusion: Civilian primary care physicians are often the first practitioners consulted by veterans and their spouses/partners about war-related conditions. Findings reveal a clear need to enhance their capacity to treat this population. Trainings should: improve providers' screening for military/veteran status, increase knowledge of best practices for treating war-related conditions, enhance physician confidence in providing care, and improve coordination of treatment between VA and civilian health providers.

Keywords Veterans; Veteran health care; Internal medicine; Family medicine; Primary care physicians; Traumatic Brain Injury (TBI); Post-Traumatic Stress Disorder (PTSD); Veteran families; Iraq; Afghanistan

\section{Introduction}

Veterans of the recent wars in Afghanistan and Iraq face a number of health challenges as they attempt to reintegrate to civilian life [1]. Many of these veterans and their family members seek treatment from civilian primary care providers in their communities, but their military background may go undetected [2,3]. It is commonly assumed that most veterans obtain health treatment from the Veterans Administration (VA), but the benefits for many are limited to five years after discharge [3]. Others have private insurance through employers or choose to continue care with trusted physicians in the TRICARE network, the health insurance program managed by the Defense Health Agency. Long distances to VA facilities and the stigma associated with mental health treatment are other barriers to seeking care [1]. Only about $40 \%$ of veterans of Operation Enduring Freedom
(OEF) and Operation Iraqi Freedom (OIF) who are eligible to receive VA health services obtain this care [4]. Moreover, federal policymakers recently expanded VA beneficiaries' access to private, community-based health providers because of capacity constraints within the VA health system [5].

Given that civilian primary care physicians are often the first level of contact for recent veterans with physical and psychological health concerns, there is an urgent need to assess their capacity to treat veterans and their family members $[3,6]$. Yet little is known about how prepared and confident civilian physicians are in delivering health care to this population, or their interest in training to treat war-related conditions. Only two known studies have addressed civilian primary care providers' knowledge, practices, and comfort related to veteran care. One study combined primary care and behavioral health professionals in their analyses [7] and a second reported on civilian physicians, nursing professionals, and other non-physician providers in rural communities [8]. Findings from both studies underscored the need to increase patient screening for military status and to improve providers' capacity to deliver high quality, coordinated care for veterans and family members. Our study aimed to expand existing 
research by focusing on two groups of civilian physicians, those trained in internal medicine and family medicine. These groups were deemed most likely among primary care physicians to treat health conditions of OEF/OIF veterans and their spouses/partners, to develop sustained relationships with patients, and to provide treatment within the context of families and communities [9]. The current study examined these physicians' knowledge, confidence, and practices in treating war-related conditions, as well as their future training interests.

\section{Health challenges of recent veterans}

Since September 11, 2011, more than 2.6 million American service members have deployed to Afghanistan and Iraq [10], and approximately 1.6 million have separated from the military and become veterans [4]. Recent veterans have experienced unique health challenges, including violent combat, improvised explosive device (IED) blasts, hazardous living conditions, and handling of human remains [10]. Although the majority transition successfully to civilian life, large numbers of veterans have sought treatment for musculoskeletal problems, mental health conditions, and "nonspecific signs and symptoms" (e.g., fatigue, cognitive complaints) [6]. Chronic pain caused by musculoskeletal injuries has been common in this population; in one study, more than a quarter $(28 \%)$ of OEF/OIF veterans reported moderate to severe pain [11]. The prevalence of Traumatic Brain Injury (TBI), a "signature condition" of the recent wars, has been estimated to be $10-20 \%$ among OEF/OIF veterans $[1,6]$. TBIs have been linked to numerous cognitive, emotional, and behavioral problems, including poor concentration, impaired memory, headaches, vision and hearing problems, irritability, and sleep disturbances [6].

Combat deployments have also been linked to psychological trauma, contributing to conditions such as Post Traumatic Stress Disorder (PTSD). An estimated $20 \%$ of service members deployed to Iraq and Afghanistan have exhibited symptoms of PTSD or depression, and others have reported anxiety, sleep disorders, substance abuse, and suicidal ideation [1]. As many as 33\% of recent women veterans have reported experiencing Military Sexual Trauma (MST) [12]. Comorbid mental and physical health conditions stemming from exposure to traumatic events are also common among recent combat veterans [1]. Notably, more than half of OEF/OIF veterans are married [13]. Veteran reunification challenges, including accommodating to physical and psychological war injuries, have been associated with increased marital instability, spousal depression, domestic abuse, and caregiver burden [14-17].

\section{Objectives}

Responding to these challenges, the state of Maryland has addressed the health needs of Maryland veterans and their families through Maryland's Commitment to Veterans, a resource and referral initiative of the Maryland Department of Health and Mental Hygiene (DHMH) [18]. Home to approximately 450,000 veterans, the State predicts its current cohort of $46,000 \mathrm{OEF} / \mathrm{OIF}$ veterans will grow to 76,000 by 2020 [19]. In 2012, DHMH partnered with the University of Maryland (UMD) School of Public Health to assess the needs of civilian behavioral health [20] and primary care providers who had the potential to treat veterans and their families. The current study aimed to: 1) assess internists' and family physicians' knowledge, confidence, and screening and referral practices in treating veterans and adult family members for war-related conditions, 2) determine whether or not there were differences in physicians' preparation as a function of their area of medical/residency training; and 3) identify respondents' interest in future training to treat military-related health conditions.

\section{Method}

\section{Data source and sample}

In fall 2012, the UMD Institutional Review Board approved the needs assessment study of health providers' treatment of veterans and family members. The Maryland Board of Physicians agreed to send their members one email announcing the survey. A message from the Secretary of DHMH targeting primary care physicians explained the study's purpose and encouraged primary care physicians to complete the voluntary, anonymous, 15-minute survey. No monetary incentives were offered. Physicians were informed that completion of the survey implied their consent to participate in the research. Those who elected to participate were linked to an online survey that was closed after two months.

This study considered only the responses of internists and family physicians. Geriatricians and pediatricians were excluded because of the focus on treatment of OEF/OIF veterans and their adult partners. Completed surveys were received from 156 internists and family physicians. Providers who worked at military installations/facilities or were serving on active duty $(n=11)$ were excluded because of the focus on civilian professionals. The vast majority of respondents worked in community-based private practices, but 20 reported also working in hospitals. Based on board membership numbers, the response rate represented under $5 \%$ of internists and family physicians in the state. However, among primary care providers who actually opened the survey, 94\% completed and submitted it. Since the survey was anonymous, data were not available to compare respondents with non-respondents.

\section{Measure}

The needs assessment survey was adapted from a web survey developed by the VISN 6 Mental Illness Research, Education and Clinical Center and the Office of Rural Health, which had been successfully disseminated by professional organizations and state agencies [7]. The survey collected respondents' demographic information and questioned them about treatment of veterans and family members within the last year, including 1) screening and referral practices, 2) knowledge of best practices for treating 14 warrelated conditions, 3 ) confidence in treating specific conditions, and 4) future training interests. Knowledge items (e.g., chronic pain, PTSD) were rated on a 3-point scale that included minimal, some, and extensive knowledge. Assessment of confidence in treatment addressed the same conditions on a 3-point scale with alternatives of minimally, somewhat, and very confident. Interest in future training to treat each condition was measured with response categories of not, somewhat, and very interested. The survey had excellent face validity, as assessed by the project's Advisory Council, which included 25 representatives of key federal, state, and community veteran-serving agencies/organizations [20].

\section{Statistical analyses}

Descriptive statistics were calculated to provide a demographic profile of the sample and to summarize physicians' screening and referral practices, knowledge, and confidence in treating 14 veteran/ 
Citation: Koblinsky SA, Hrapczynski KM, Leslie LA (2015) Treating Veterans of Iraq and Afghanistan: A State Needs Assessment of Civilian Physicians in Internal and Family Medicine. J Gen Practice 3: 195. doi:10.4172/2329-9126.1000195

Page 3 of 8

family member conditions, as well as their training interests. Chi squares and Fisher's exact tests were then used to test for significant differences in the proportion of internists and family physicians who reported high, some, or minimal knowledge, confidence, and training interest with regard to the 14 health conditions.

\section{Results}

\section{Characteristics of sample}

Demographic characteristics of the sample, which included 67 internists and 78 family physicians, are presented in Table 1 . Almost half (49\%) of internists and $40 \%$ of family physicians were 55 years of age or older. Respondents represented a diversity of racial/ethnic backgrounds, and approximately $89 \%$ of internists and $83 \%$ of family physicians were female. Family physicians were significantly more likely to be veterans than internists, with $17 \%$ having served in the Armed Forces $\left(\lambda^{2}=3.90, \mathrm{p}<.05\right)$. Internists were significantly more likely than family physicians to have trained in a DOD or VA facility, with $42 \%$ of internists and $22 \%$ of family physicians reporting some DOD or VA work experience $\left(\lambda^{2}=7.01, \mathrm{p}<.01\right)$. Family physicians (25\%) were significantly more likely than internists $(13 \%)$ to work in rural areas $\left(\lambda^{2}=8.14, \mathrm{p}<.05\right)$, but practice settings were generally representative of Maryland's rural-urban population, which is $13 \%$ rural [21].

\begin{tabular}{|c|c|c|}
\hline Survey Item & Internal Medicine $n=67$ & Family Medicine $n=78$ \\
\hline \multicolumn{3}{|l|}{ Age } \\
\hline $25-40$ & $18 \%$ & $21 \%$ \\
\hline $41-54$ & $33 \%$ & $39 \%$ \\
\hline $55+$ & $49 \%$ & $40 \%$ \\
\hline \multicolumn{3}{|l|}{ Race/Ethnicity ${ }^{a}$} \\
\hline White & $72 \%$ & $73 \%$ \\
\hline African American & $12 \%$ & $17 \%$ \\
\hline Asian American & $9 \%$ & $10 \%$ \\
\hline Latino & $3 \%$ & $1 \%$ \\
\hline Native American & $2 \%$ & $1 \%$ \\
\hline Other & $2 \%$ & $0 \%$ \\
\hline \multicolumn{3}{|l|}{ Sex } \\
\hline Male & $8 \%$ & $10 \%$ \\
\hline Female & $89 \%$ & $83 \%$ \\
\hline Not identified & $3 \%$ & $6 \%$ \\
\hline \multicolumn{3}{|l|}{ Military Status ${ }^{a}$} \\
\hline Veteran & $6 \%$ & $17 \%{ }^{*}$ \\
\hline Immediate family member of veteran & $23 \%$ & $17 \%$ \\
\hline \multicolumn{3}{|l|}{ Military Training/Experience } \\
\hline Any training in a VA/DOD facility & $42 \%$ & $22 \%{ }^{* *}$ \\
\hline Any VA/DOD employment & $17 \%$ & $18 \%$ \\
\hline \multicolumn{3}{|l|}{ Professional Location } \\
\hline Rural & $13 \%$ & $25 \%{ }^{*}$ \\
\hline Urban & $87 \%$ & $75 \%$ \\
\hline \multicolumn{3}{|l|}{ Patient Population in Past Year ${ }^{a}$} \\
\hline Veterans & $67 \%$ & $75 \%$ \\
\hline Active Duty & $33 \%$ & $21 \%$ \\
\hline
\end{tabular}


Citation: Koblinsky SA, Hrapczynski KM, Leslie LA (2015) Treating Veterans of Iraq and Afghanistan: A State Needs Assessment of Civilian Physicians in Internal and Family Medicine. J Gen Practice 3: 195. doi:10.4172/2329-9126.1000195

Page 4 of 8

\begin{tabular}{|c|c|c|}
\hline Survey Item & Internal Medicine $n=67$ & Family Medicine $n=78$ \\
\hline National Guard/Reserves & $25 \%$ & $30 \%$ \\
\hline Family members of veterans & $50 \%$ & $61 \%$ \\
\hline \multicolumn{3}{|l|}{ Accept TRICARE } \\
\hline Yes, accept & $51 \%$ & $53 \%$ \\
\hline No, does not accept & $25 \%$ & $26 \%$ \\
\hline Unsure & $24 \%$ & $21 \%$ \\
\hline \multicolumn{3}{|l|}{ Screen for Military/Veteran/Family Member Status } \\
\hline Yes, regularly & $27 \%$ & $24 \%$ \\
\hline Yes, occasionally & $15 \%$ & $14 \%$ \\
\hline No & $58 \%$ & $62 \%$ \\
\hline \multicolumn{3}{|l|}{ Ask Veterans about Stressors of Military Service } \\
\hline Yes, regularly & $29 \%$ & $35 \%$ \\
\hline Yes, occasionally & $32 \%$ & $31 \%$ \\
\hline No & $39 \%$ & $35 \%$ \\
\hline \multicolumn{3}{|c|}{ Ask Family Members about Military-related Stressors } \\
\hline Yes, regularly & $23 \%$ & $25 \%$ \\
\hline Yes, occasionally & $35 \%$ & $33 \%$ \\
\hline No & $42 \%$ & $42 \%$ \\
\hline \multicolumn{3}{|l|}{ Frequency of Referral to VA } \\
\hline Often & $10 \%$ & $13 \%$ \\
\hline Sometimes & $49 \%$ & $42 \%$ \\
\hline Never & $41 \%$ & $45 \%$ \\
\hline \multicolumn{3}{|l|}{ Factors that Prevent Referral to $\mathrm{VA}^{\mathrm{a}}$} \\
\hline Lack of knowledge about eligibility requirements & $32 \%$ & $28 \%$ \\
\hline Lack of knowledge about how to refer & $20 \%$ & $19 \%$ \\
\hline Concerns about wait time for appointments & $18 \%$ & $14 \%$ \\
\hline Concerns about quality of care & $12 \%$ & $11 \%$ \\
\hline Clients not eligible for VA services & $1 \%$ & $4 \%$ \\
\hline Concerns about distance to nearest VA & $2 \%$ & $3 \%$ \\
\hline \multicolumn{3}{|l|}{ Preferred Training Modalities ${ }^{a}$} \\
\hline Face-to-face workshop & $81 \%$ & $79 \%$ \\
\hline Webinar & $64 \%$ & $58 \%$ \\
\hline \multicolumn{3}{|l|}{$\begin{array}{l}\text { aParticipants could check all responses that applied. } \\
{ }^{* *} p<.01,{ }^{*} p<.05\end{array}$} \\
\hline
\end{tabular}

Table 1: Characteristics of sample of primary care physicians $(\mathrm{N}=145)$. 
Citation: Koblinsky SA, Hrapczynski KM, Leslie LA (2015) Treating Veterans of Iraq and Afghanistan: A State Needs Assessment of Civilian Physicians in Internal and Family Medicine. J Gen Practice 3: 195. doi:10.4172/2329-9126.1000195

Page 5 of 8

\section{Prior Treatment of veterans and family members}

Table 1 also presents data on respondents' treatment of veterans and family members in their practices. Two-thirds of internists and three quarters of family physicians reported treating veterans, and at least $50 \%$ of both groups treated veteran family members in the past year. Approximately half of both groups reported accepting TRICARE, but $24 \%$ of internists and $21 \%$ of family physicians were unsure about whether their practice participated in this health program.

When asked about their screening of patients or family members for military/veteran status, it is notable that only $27 \%$ of internists and $24 \%$ of family physicians regularly conducted such screening. Moreover, $58 \%$ of internists and $62 \%$ of family physicians never screened for military/veteran background. Physicians were slightly more likely to ask about military-related stressors when patients identified as veterans ( $29 \%$ internists, $35 \%$ family physicians), but only about a quarter posed similar questions to family members. When queried about VA referrals, only $10 \%$ of internists and $13 \%$ of family physicians often referred patients to the VA; $41 \%$ of internists and $45 \%$ of family physicians had never made a VA referral. The most common reasons for failure to refer were lack of knowledge about eligibility requirements and how to refer, followed by concerns about wait time for appointments and quality of care.

\section{Knowledge about treating veteran conditions}

Chi square and Fisher exact tests revealed no significant differences in the proportions of internists and family physicians who reported high, some, or minimal knowledge, confidence, and training interest related to any of the 14 targeted health conditions. Additionally, there were no significant differences in any outcomes between physicians who worked in community-based private practices and a smaller group (20) who reported working in both hospitals and outpatient practices. Thus, Table 2 summarizes these data for the combined group of 145 primary care providers. With respect to knowledge of treatments for military-related conditions, only $21 \%$ or fewer physicians reported extensive knowledge of best practices for treating any of the 14 conditions. However, considerably more (between $31 \%$ and 58\%) reported possessing some knowledge of these treatments. Overall, respondents were most likely to report extensive knowledge of treating chronic pain, depression, anxiety, substance abuse/ dependence, and caregiver stress (20-21\%), and least likely to report extensive knowledge of best practices for treating MST (5\%), family violence (12\%), TBI (14\%), suicidal ideation (15\%), and anger (15\%).

\begin{tabular}{|c|c|c|c|c|c|c|c|c|c|}
\hline & \multicolumn{3}{|c|}{ Knowledge } & \multicolumn{3}{|c|}{ Confidence } & \multicolumn{3}{|c|}{ Training Interest } \\
\hline & High & Some & Minimal & High & Some & Minimal & High & Some & None \\
\hline \multicolumn{10}{|c|}{ Issue/Condition of Veteran or Family Member } \\
\hline Anger & $15 \%$ & $47 \%$ & $38 \%$ & $13 \%$ & $36 \%$ & $51 \%$ & $36 \%$ & $56 \%$ & $8 \%$ \\
\hline Anxiety & $21 \%$ & $55 \%$ & $24 \%$ & $19 \%$ & $51 \%$ & $30 \%$ & $36 \%$ & $57 \%$ & $7 \%$ \\
\hline Caregiver Stress & $21 \%$ & $49 \%$ & $30 \%$ & $17 \%$ & $46 \%$ & $37 \%$ & $38 \%$ & $56 \%$ & $6 \%$ \\
\hline Depression & $21 \%$ & $58 \%$ & $21 \%$ & $18 \%$ & $50 \%$ & $32 \%$ & $41 \%$ & $53 \%$ & $6 \%$ \\
\hline $\begin{array}{l}\text { Family Stress and Relationship } \\
\text { Problems }\end{array}$ & $19 \%$ & $53 \%$ & $28 \%$ & $13 \%$ & $39 \%$ & $48 \%$ & $38 \%$ & $54 \%$ & $8 \%$ \\
\hline Family Violence & $12 \%$ & $48 \%$ & $40 \%$ & $7 \%$ & $36 \%$ & $57 \%$ & $37 \%$ & $54 \%$ & $9 \%$ \\
\hline Grief and Bereavement & $18 \%$ & $51 \%$ & $31 \%$ & $17 \%$ & $41 \%$ & $42 \%$ & $36 \%$ & $58 \%$ & $6 \%$ \\
\hline Military Sexual Trauma & $5 \%$ & $31 \%$ & $64 \%$ & $5 \%$ & $22 \%$ & $73 \%$ & $35 \%$ & $52 \%$ & $13 \%$ \\
\hline Pain Management & $20 \%$ & $53 \%$ & $27 \%$ & $21 \%$ & $43 \%$ & $36 \%$ & $45 \%$ & $45 \%$ & $10 \%$ \\
\hline Post Traumatic Stress Disorder & $19 \%$ & $53 \%$ & $28 \%$ & $10 \%$ & $39 \%$ & $51 \%$ & $52 \%$ & $43 \%$ & $5 \%$ \\
\hline Sleep Disorders & $17 \%$ & $55 \%$ & $28 \%$ & $14 \%$ & $47 \%$ & $39 \%$ & $45 \%$ & $46 \%$ & $9 \%$ \\
\hline $\begin{array}{l}\text { Substance Abuse and } \\
\text { Dependence }\end{array}$ & $21 \%$ & $54 \%$ & $25 \%$ & $14 \%$ & $39 \%$ & $47 \%$ & $37 \%$ & $51 \%$ & $12 \%$ \\
\hline Suicide and Suicidal Ideation & $15 \%$ & $55 \%$ & $30 \%$ & $12 \%$ & $38 \%$ & $50 \%$ & $42 \%$ & $50 \%$ & $8 \%$ \\
\hline Traumatic Brain Injury & $14 \%$ & $39 \%$ & $47 \%$ & $11 \%$ & $25 \%$ & $64 \%$ & $45 \%$ & $44 \%$ & $11 \%$ \\
\hline
\end{tabular}

Table 2: Physicians' knowledge, confidence, and training interests regarding best practices for treating veterans and family members ( $\mathrm{N}=145$ ). 


\section{Confidence in treating conditions}

With respect to confidence for treating the target conditions, Table 2 reveals that only $21 \%$ or fewer of respondents felt "very" confident about treating each of the 14 target conditions. Physicians were generally most confident about treating conditions for which they had the most knowledge (e.g., chronic pain, depression, anxiety). Between $36 \%$ and $51 \%$ of respondents reported feeling "somewhat" confident in treating 12 of the 14 conditions. However, $50 \%$ or more felt minimally competent in treating TBI, MST, PTSD, suicidal ideation, anger, and family violence.

\section{Interest in training}

Finally, physicians were asked about their interest in future training about treatment of veterans' health conditions. As shown in Table 2, approximately nine out of ten respondents reported being "very" or "somewhat" interested in obtaining training on all of the targeted health conditions. Between $40 \%$ and $52 \%$ of physicians reported having high interest in obtaining future training on best practices for treating chronic pain, TBI, sleep disorders, PTSD, depression and suicidal ideation. In response to questions about preferred training modalities, Table 1 reveals that $81 \%$ of internists and $79 \%$ of family physicians expressed interest in face-to-face trainings, while $64 \%$ of internists and $58 \%$ of family physicians reported similar interest in webinars.

\section{Discussion}

To our knowledge, this study represents the first statewide needs assessment of civilian primary care providers' capacity to treat warrelated conditions that may affect OEF/OIF veterans and their adult family members. Given that internists and family physicians are generally the first point of contact for veterans and spouses experiencing health problems, and may serve as "de facto" mental health professionals [3], they play a critical role in veteran and family member care [3]. The numbers of veterans and family members seeking care in civilian primary care settings is expected to grow as a result of the drawdown of troops in Afghanistan, the downsizing of the U.S. military [22], and the delayed onset of some veteran health conditions (e.g., PTSD) following trauma exposure [1]. Research reveals that many recent veterans have sought treatment from community-based civilian providers rather than federal government services because they are thought to be more accessible, flexible and confidential [23-25].

Current findings enabled comparisons of the internists and family physicians within our sample, and revealed no significant differences in physicians' knowledge and confidence to treat the targeted conditions related to their medical training. It was also interesting to compare responses from our total sample of primary care physicians with those of civilian mental health professionals who completed the same state survey [20]. Notably, the vast majority (86\%) of primary care respondents were women, although women represent only $40 \%$ of internists and $51 \%$ of family physicians in the state. More than $80 \%$ of respondents in the study of civilian mental health professionals were women, but women represent more than two thirds of psychologists, social workers, counselors, and marriage and family therapists in Maryland. As in the larger mental health provider study, more than $40 \%$ of internists and family physicians were age 55 or older. Older providers may have acquired experience in treating veterans of other war eras [8], but may also lack training in evidence-based treatments for signature conditions of OEF/OIF, such as PTSD, TBI, and MST [26]. When compared to their peers in the mental health professions [20], primary care physicians in our sample were more likely to be veterans, to have received training in a VA/DOD facility, and to have been employed by the VA/DOD. However, the majority of physician respondents lacked formal military training and experience, suggesting limited familiarity with military culture and its associated values, traditions, language, and life styles.

Findings further revealed that a majority of internists and family physicians had treated veterans and family members as patients in the past year, and many had also treated active duty service members. A quarter of physicians reported being non-participants in TRICARE and more than a fifth were unsure of their status as TRICARE providers, indicating that additional physicians in the state would benefit from learning more about this source of health insurance. All civilian primary care providers should also become familiar with the new Defense Health Agency, which recently assumed many functions of TRICARE within a larger initiative to offer more integrated military health services [27].

Given the large percentage of civilian physicians who treated veterans and family members, it is noteworthy that only about a quarter regularly screened patients for their military/veteran status and approximately six out of ten never screened for military background. Approximately four out of ten civilian physicians reported failing to question veterans and family members about military-related stressors. Results are consistent with previous research indicating low levels of screening by primary care and mental health providers for military background and combat experiences $[7,8,20]$. Findings illustrate the need for physicians to routinely screen for patients' military history or membership in a veteran/military family, and to identify service-related stressors that influence individual health and family relationships. Questions may be as simple as "Have you or someone close to you served in the Armed Forces?" [7]. Physicians may also use short, psychometrically validated screening measures to assess combat exposure/trauma, PTSD, depression, suicidal ideation, and other health conditions [28]. Screening will improve physicians' ability to make informed diagnoses, develop treatment plans, and/or refer patients to the VA or other civilian providers. Brief discussions of military experience may also reveal veteran and family member strengths that facilitate treatment, improve physician-patient relationships, and increase adherence to treatment.

Our findings also reported on civilian physicians' referrals to the VA. As in the study of the state's mental health professionals [20], only one in eight or fewer physicians regularly referred patients to the VA, and more than four in ten had never made a VA referral for any health care need. Insufficient knowledge about VA eligibility and VA referral processes were the most common reasons for failure to refer. Findings reveal a clear need to educate more physicians about VA eligibility, services, and referral procedures. Greater collaboration between the VA and civilian physicians may provide recent veterans with opportunities for culturally-competent care of conditions that many physicians do not typically treat/manage in their practices (e.g., MST, substance abuse disorders, suicidal thoughts/behaviors) [20]. Primary care physicians should also have information about area mental health professionals with expertise in veteran/family member care so they can make appropriate referrals when deemed necessary.

A major objective of this study was to examine primary care physicians' knowledge and confidence in treating service-related conditions. Notably, only about a fifth of primary care respondents to 
Page 7 of 8

our survey reported high levels of knowledge or confidence in treating any of the 14 targeted health conditions. Physicians reported the least knowledge and confidence for treating TBI and MST, two signature conditions of the OEF/OIF conflicts [1]. Approximately one in five physicians reported high knowledge of best practices for treating PTSD, but only about half that number felt very confident in treating this condition. A previous study of primary care providers with OEF/OIF patients found that PTSD was the least likely of seven behavioral health conditions (e.g., depression, bereavement, substance abuse) to be treated in a primary care setting; only $35 \%$ of the primary care providers reported treating PTSD in their practices [8]. However, the majority $(60 \%)$ of providers in the latter study utilized diagnostic mental health screeners and over three quarters (78\%) prescribed psychotropic drugs for mental health issues frequently or occasionally.

Current findings parallel those of previous research that surveyed physicians and non-physician primary care providers [8], civilian mental health providers $[20,26]$, and a combined group of mental health and primary care providers [7] about their readiness to treat veterans and their families. When compared to the sample of mental health providers who took the identical survey in our state, primary care providers reported having slightly higher knowledge and confidence in treating chronic pain, sleep disorders, and TBI. In contrast, mental health providers felt more knowledgeable and confident in treating all of the mental health conditions. While it is not surprising that many primary care physicians felt ill-prepared to treat veterans' mental health conditions, research confirms that they see many veterans and spouses/partners with mental health problems in their practices $[7,8]$. In one prior study of primary care professionals treating OEF/OIF veteran families over a six-month period, physicians reported that $28 \%$ of veterans and $59 \%$ of their family members had mental health problems [8]. The most frequently reported problems were generalized anxiety, major depression, and family and marital problems [8]. In another study of OEF/OIF era military families, spouses were more likely to seek care for mental health problems than service members, and the majority received treatment only from military or civilian primary care providers [29]. These findings underscore the need to screen both veterans and their spouses/ partners for mental and physical health conditions. Treatment of family members for psychological distress is especially important given their critical role in facilitating veteran recovery from war wounds [30].

Both this study and prior research indicate that many civilian primary care physicians would benefit from additional training on treatment of war-related health conditions. As noted, such training may not have been included in medical/graduate school curricula, and several new therapies for treating traumatic experiences are only now under study [24,26]. Our study reveals that a substantial proportion of internists and family physicians are motivated to obtain such training. Specifically, $40 \%$ to $50 \%$ of respondents reported the highest level of interest in attending trainings that addressed best-practice treatments for PTSD, depression, TBI, chronic pain management, and suicidal ideation. Only about one in ten physicians reported no interest in obtaining training on any of the targeted health conditions. Interestingly, the most popular training modality reported by primary care physicians was face-to-face trainings, followed by webinars. Faceto-face trainings may enable physicians to develop local networks of primary care and mental health providers, and to share treatment techniques for common, military-related conditions. Webinars offer the advantage of reduced time and travel costs for busy professionals.

\section{Limitations}

Although our study provides important insights about the preparedness of civilian primary care physicians to treat OEF/OIF veterans and family members, it has several limitations. The sample size was small and the response rate was low. Additionally, there was an overrepresentation of women physicians among our respondents, so results may not be representative of the state's larger population of primary care physicians. Respondents may have had a special interest in veterans' issues not shared by their peers, or it is possible that physicians well-trained to treat this population did not respond. Results may have also overrepresented physicians' knowledge through their desire to present themselves in a favorable light. However, the survey was anonymous and completed by the vast majority of physicians who opened the email invitation. Moreover, findings were generally consistent with those obtained in several previous studies of health care providers $[7,8,20]$. Given how little is known about civilian physicians' knowledge, confidence, and practices in treating veterans and their families, this statewide study may serve as a springboard for future research.

Future needs assessment studies should aim for larger samples and higher response rates, securing the endorsement of medical societies and professional associations. Studies should also assess training needs of civilian hospitalists and primary care physicians in other states/ regions, including those that vary in size and geographic distribution (rural-urban) of the veteran population. Future use of qualitative research methods may also increase understanding of the complexities of screening, treating, and referring recent veterans and family members in busy primary care practices.

\section{Conclusion}

Primary care physicians in internal and family medicine will increasingly encounter OEF/OIF veterans and adult family members in their community-based practices. There is now a critical need to enhance civilian physicians' readiness to treat the unique health challenges of this population. Routine screening for military status/ affiliation and continuing education on best practices for treating warrelated conditions will better prepare physicians for veteran and family member care. Efforts should also be made to strengthen care coordination between civilian primary care physicians, mental health providers, and the VA. Such strategies have the potential to facilitate timely intervention and to reduce the personal and societal costs of untreated health conditions. Veterans and their families have made major sacrifices for our nation and deserve accessible, high-quality, and well-integrated patient care.

\section{Acknowledgement}

The authors gratefully acknowledge Dr. Emily Cook, Dr. Xin He, and Emma Murray for their assistance with data collection and analyses.

\section{Funding}

This research was supported by the Maryland Department of Health and Mental Hygiene (12-10982G). The views expressed are entirely those of the authors and do not necessarily represent the official position of the Department of Health and Mental Hygiene. 
Citation: Koblinsky SA, Hrapczynski KM, Leslie LA (2015) Treating Veterans of Iraq and Afghanistan: A State Needs Assessment of Civilian Physicians in Internal and Family Medicine. J Gen Practice 3: 195. doi:10.4172/2329-9126.1000195

Page 8 of 8

\section{References}

1. Tanielian T, Jaycox LH (2008) Invisible wounds of war: Psychological and cognitive injuries, their consequences, and services to assist recovery. RAND Corporation, Santa Monica, CA.

2. Seehusen DA (2010) Screening for veteran status in the primary care setting. J Am Board Fam Med 23: 700-701.

3. Hinojosa R, Sberna Hinojosa M, Nelson K, Nelson D (2010) Veterans family reintegration, primary care needs, and the benefit of the patientcentered medical home model. J Am Board Fam Med 23: 770-774.

4. Bagalman E (2013) Mental disorders among OEF/OIF veterans using VA health care: Facts and figures. Congressional Research Service, USA.

5. Veterans' Access to Care through Choice, Accountability and Transparency Act of 2014, Public Law No. 114-146 (2014).

6. Spelman JF, Hunt SC, Seal KH, Burgo-Black AL (2012) Post deployment care for returning combat veterans. J Gen Intern Med 27: 1200-1209.

7. Kilpatrick DG, Best CL, Smith DW, Kudler H, Cornelison-Grant V (2011) Serving those who have served: Educational needs of health care providers working with military members veterans, and their families. National Crime Victims Research \& Treatment Center, Medical University of South Carolina Department of Psychiatry.

8. Boscarino JA, Larson S, Ladd I, Hill E, Paolucci SJ (2010) Mental health experiences and needs among primary care providers treating OEF/OIF veterans: preliminary findings from the Geisinger Veterans Initiative. Int J Emerg Ment Health 12: 161-170.

9. Donaldson MS, Yordy KD, Lohr KN, Vanselow NA (1996) Primary care: America's health in a new era. National Academy Press, Washington D.C.

10. National Research Council (2013) Returning home from Iraq and Afghanistan: Assessment of readjustment needs of veterans, service members, and their families. The National Academies Press, Washington, D.C.

11. Gironda RJ, Clark ME, Massengale JP, Walker RL (2006) Pain among veterans of Operation Enduring Freedom and Iraqi Freedom. Pain Med 7: 339-343.

12. Department of Defense (2013) Department of Defense annual report on sexual assault in the military: Fiscal year 2012. Author, Washington, D.C.

13. Department of Defense (2012) 2011 demographics: Profile of the military community. Author, Washington, D.C.

14. Family Caregiver Alliance (2010) Fact sheet: Selected caregiver statistics.

15. Sayers SL, Farrow VA, Ross J, Oslin DW (2009) Family problems among recently returned military veterans referred for a mental health evaluation. J Clin Psychiat 70: 163-170.
16. National Alliance for Caregiving (2010) Caregivers of veterans - Serving on the homefront. Author, Bethesda, MD.

17. Taghva A, Dabbaghi P, Shafighi S, Mortazaviha SMA, Donyavi V (2014) Mental health in spouses of Iraq-Iran war veterans with PTSD. JAMM 2: e17010.

18. Maryland Department of Health and Mental Hygiene (2013) Maryland's Commitment To Veterans.

19. U.S. Department of Veterans Affairs (2012) Veteran population.

20. Koblinsky SA, Leslie LA, Cook ET (2014) Treating behavioral health conditions of OEF/OIF veterans and their families: A state needs assessment of civilian providers. Mil Behav Health 4: 162-172.

21. Maryland Department of Planning (2010) Maryland State Data Center, Rural and Urban designation by jurisdiction.

22. National Council for Behavioral Health (2012) Meeting the behavioral health needs of veterans of Operations Enduring Freedom and Operation Iraqi Freedom. Author, Washington D.C.

23. Davis LL, Kertesz SG, Mahaney-Price AF, Martin MY, Tabb KD, et al. (2011) Alabama veterans rural health initiative: A preliminary evaluation of unmet health care needs. J Rural Soc Sci 26: 14-31.

24. Greedlinger R, Clervil R (2011) Engaging veterans and families to enhance service delivery. National Center on Family Homelessness, Waltham, MA.

25. Schell TL, Tanielian T, Farmer CM, Jaycox LH, Marshall GN, et al. (2011) A needs assessment of New York State veterans. RAND Health Quarterly 1:1.

26. Tanielian T, Farris C, Epley C, Farmer C, Robinson E, et al. (2014) Ready to serve: Community-based provider capacity to deliver culturally competent, quality mental health care to veterans and their families. RAND Corporation, Santa Monica, CA.

27. Military Health System (2014) Defense Health Agency.

28. U.S. Department of Veterans Affairs (2013) VA/DOD clinical practice guidelines.

29. Easton KM, Hoge CW, Messer SC, Whitt AA, Cabrera OA, et al. (2008) Prevalence of mental health problems, treatment need, and barriers to care among primary care-seeking spouses of military service members involved in Iraq and Afghanistan deployments. Mil Med 173: 1051-1056.

30. Cozza SJ, Holmes AK, Van Ost SL (2013) Family-centered care for military and veteran families affected by combat injury. Clin Child Fam Psychol Rev 16: 311-321. 